\title{
Silent sinus syndrome
}

\author{
Mohammed Bahgat, Yassin Bahgat, Ahmed Bahgat
}

Department of ENT and Head \& Neck Surgery, Alexandria University Hospitals, Alexandria, Egypt

Correspondence to Mohammed Bahgat, mybahgat18@hotmail.com

\section{DESCRIPTION}

A 35-year-old male patient presented to our clinic complaining of a 2-week history of progressive left cheek depression causing visible asymmetry of the face and the sensation of his left eye 'sinking in' for the previous 5 days. The patient had a history of minor bilateral intermittent nasal obstruction symptoms and slight rhinorrhoea. On examination enophthalmos of the left eye and facial asymmetry were observed (figure 1).

CT scans of the orbit and the nose and paranasal sinuses showed complete opacification and collapse of the left maxillary sinus with inferior bowing of the orbital floor (figure 2).

The patient was diagnosed to have silent sinus syndrome (SSS). Patency of maxillary sinus ostium was

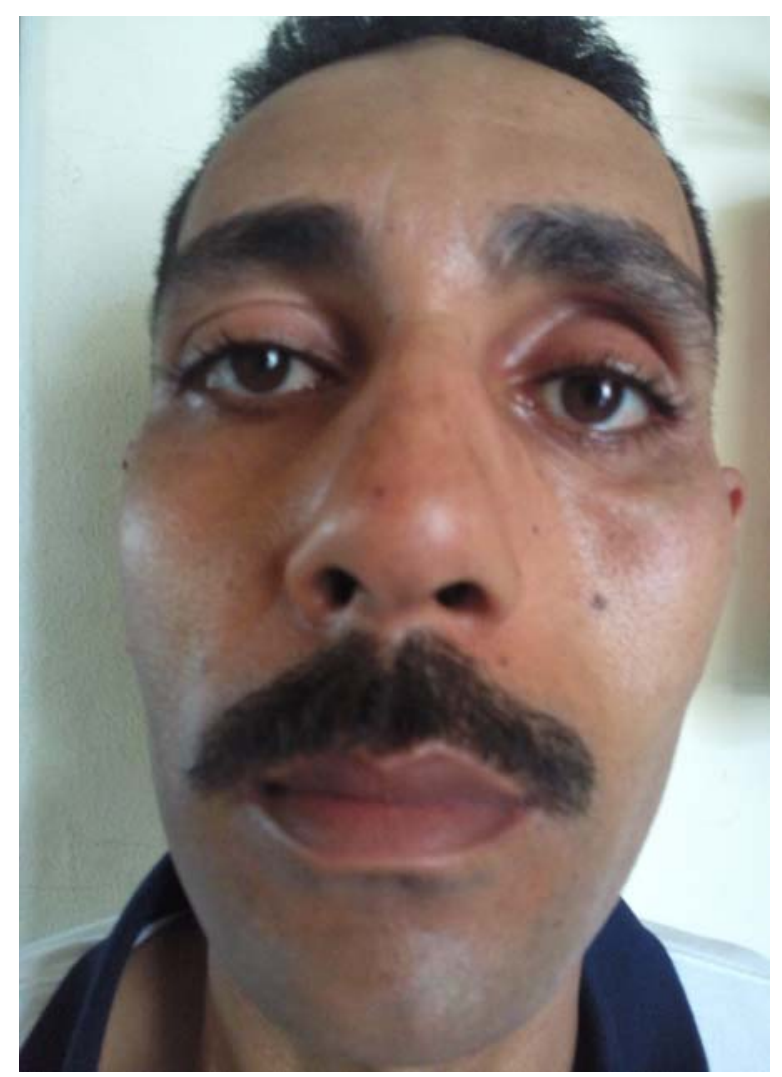

Figure 1 Left-eye enophthalmos and progressive left cheek depression causing visible asymmetry of the face. achieved with an endoscopic approach under general anaesthesia. Six months after the operation the patient is free from orbital or sinus disturbance.

SSS is an acquired spontaneous unilateral maxillary atelectasis with complete or partial opacification of the sinus associated with spontaneous, painless enophtalmos and progressive hypoglobus. It is a very uncommon pathology. 12

Physical examination findings may include upper lid retraction, deepened upper lid sulcus, malar depression, facial asymmetry and maybe diplopia. ${ }^{12}$

The diagnosis of SSS is confirmed by CT of nose and paranasal sinuses which characteristically shows maxillary sinus opacification and collapse with inferior bowing of the orbital floor. The uncinate process is retracted against the inferomedial aspect of the orbital wall.

The management of SSS is to restore normal maxillary sinus drainage by enlarging the sinus ostium with functional endoscopic sinus surgery. ${ }^{1} 2$

\section{Learning points}

- Silent sinus syndrome (SSS) is an acquired unilateral maxillary atelectasis with complete or partial opacification of the sinus associated with enophtalmos and hypoglobus.

- The diagnosis of SSS is confirmed by CT scans of the nose and paranasal sinuses which characteristically show maxillary sinus opacification and collapse with inferior bowing of the orbital floor. The uncinate process is retracted against the inferomedial aspect of the orbital wall.

- The management of SSS is to restore normal maxillary sinus drainage by enlarging the maxillary sinus ostium with functional endoscopic sinus surgery.

Competing interests None.

Patient consent Obtained.

\section{REFERENCES}

1. Cobb AR, Murthy R, Cousin GC, et al. 'Silent sinus syndrome'. Br J Oral Maxillofac Surg 2012;50:81-5.

2. Babar-Craig H, Kayhanian H, De Silva DJ, et al. 'Spontaneous silent sinus syndrome (imploding antrum syndrome): case series of 16 patients'. Rhinology 2011:49:315-17. 


\section{BMJ Case Reports}

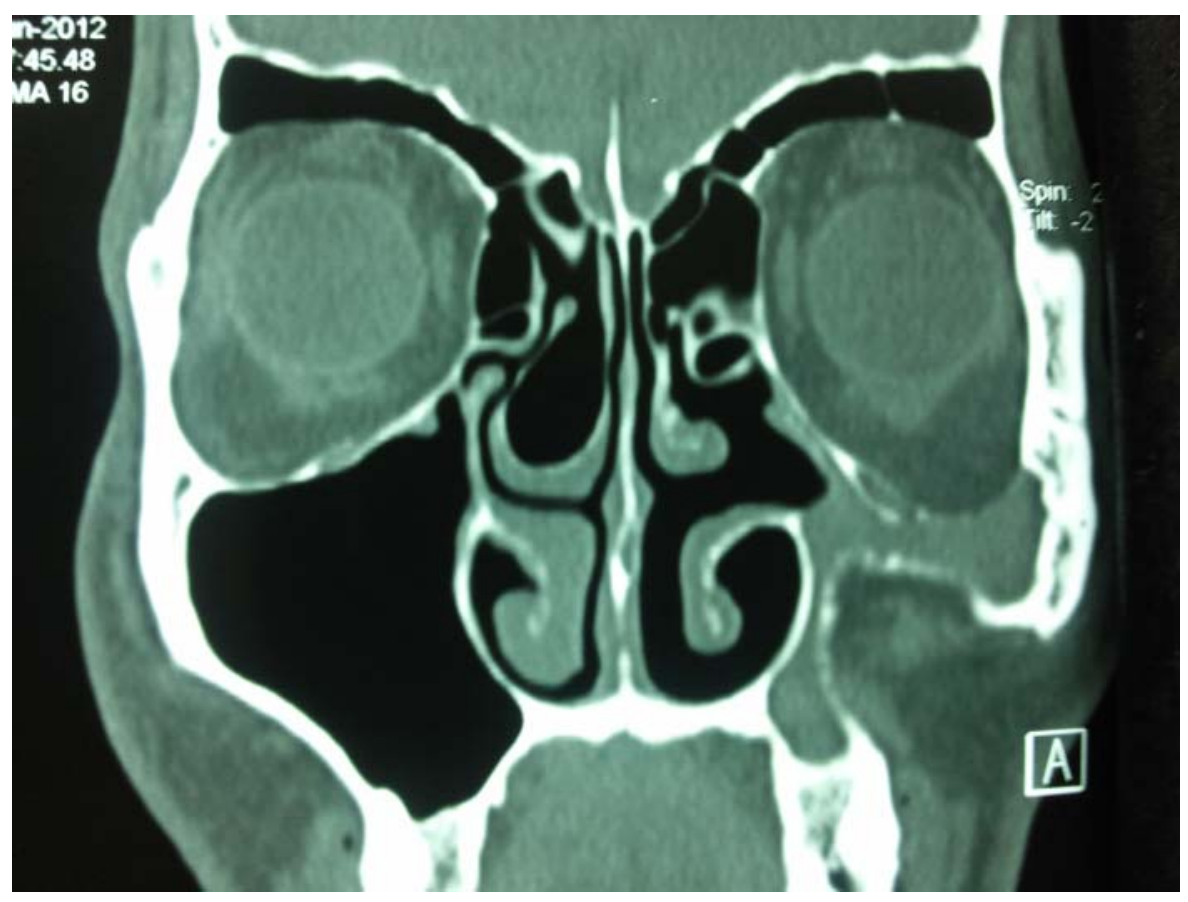

Figure 2 CT of the nose and paranasal sinuses (coronal view) showing complete opacification and collapse of the left maxillary sinus with inferior bowing of the orbital floor. Features diagnostic of left silent sinus syndrome.

Copyright 2012 BMJ Publishing Group. All rights reserved. For permission to reuse any of this content visit

http://group.bmj.com/group/rights-licensing/permissions.

BMJ Case Report Fellows may re-use this article for personal use and teaching without any further permission.

Please cite this article as follows (you will need to access the article online to obtain the date of publication).

Bahgat M, Bahgat Y, Bahgat A. Silent sinus syndrome. BMJ Case Reports 2012;10.1136/bcr-2012-007198, Published XXX

Become a Fellow of BMJ Case Reports today and you can:

- Submit as many cases as you like

- Enjoy fast sympathetic peer review and rapid publication of accepted articles

- Access all the published articles

- Re-use any of the published material for personal use and teaching without further permission

For information on Institutional Fellowships contact consortiasales@bmjgroup.com

Visit casereports.bmj.com for more articles like this and to become a Fellow 